\title{
A novel method for Isolating Nanocrystalline Cellulose from Eucalyptus Hardwood
}

\author{
Jinrong Zhang ${ }^{1}$, Wenbo Zou ${ }^{2 *}$ \\ ${ }^{1}$ The High School Affiliated to Renmin University of China, Beijing, China \\ ${ }^{2}$ National Institutes for Food and Drug Control, Beijing, China \\ Email: ^zwb@nifdc.org.cn
}

How to cite this paper: Zhang, J.R. and Zou, W.B. (2019) A novel method for Isolating Nanocrystalline Cellulose from Eucalyptus Hardwood. Journal of Analytical Sciences, Methods and Instrumentation, 9, 51-62.

https://doi.org/10.4236/jasmi.2019.93006

Received: August 22, 2019

Accepted: September 14, 2019

Published: September 17, 2019

Copyright $\odot 2019$ by author(s) and Scientific Research Publishing Inc. This work is licensed under the Creative Commons Attribution International License (CC BY 4.0).

http://creativecommons.org/licenses/by/4.0/

\begin{abstract}
The objective of this work is to develop a new method for extracting nanocrystalline cellulose (CNC) from eucalyptus. $\mathrm{CNC}$ was isolated from eucalyptus using 6:4 (v/v) tetrahydrofuran/water. The chemical and crystalline structure of the isolated $\mathrm{CNC}$ was characterized by zeta potential measurements, Fourier Transform Infrared (FT-IR) and UV-Vis spectroscopies, and $\mathrm{X}$-ray powder diffractometry. The $\mathrm{CNC}$ morphology was characterized by Transmission Electron Microscope (TEM) and particle size of CNC was determined by the Dynamic Light Scattering (DLS) method. Cytotoxicity and zebrafish-toxicity experiments were also performed on CNC. The yield of CNC using the new extraction method was about $41 \%$, and the extracted $\mathrm{CNC}$ particles were about $20 \mathrm{~nm}$ in diameter and about $40 \mathrm{~nm}$ long, on average. The zeta potential of the $\mathrm{CNC}$ was determined to be $-56 \mathrm{eV}$ and the $\mathrm{CN}$ particles were uniformly distributed in a suspension of $0.5 \mathrm{wt} \%$. The prepared $\mathrm{CNC}$ was a type I polymorph with an intact crystal structure. Toxicity results revealed that $0.5 \mathrm{wt} \%$ is a safe $\mathrm{CNC}$ concentration, and that $2.5 \mathrm{mg} / \mathrm{mL} \mathrm{CNC}$ is not teratogenic or lethal to zebrafish embryos or juveniles. The new extraction method developed in this study is environmentally friendly, and easy to operate with relatively low cost.
\end{abstract}

\section{Keywords}

Nanocrystalline Cellulose, Structure Characterization, Cytotoxicity, Zebrafish

\section{Introduction}

As an important natural polymer, cellulose is a virtually inexhaustible renewable natural resource due to its wide distribution and large reserves on earth, and is produced by photosynthesis [1]. Cellulose has been widely used in areas of med- 
icine, textiles, architecture, food, ceramics, oil, biology, and other industrial fields due to its abundant reserves, wide availability, cost effectiveness, high degree of polymerization, excellent mechanical properties, biocompatibility, and biodegradability. As a derivative of cellulose, nanocrystalline cellulose (CNC, cellulose nanocrystals) has been attracting increasing attention due to its unique mechanical and optical properties [2]. CNC is a linear polymer composed of d-glucose units linked by 1,4- $\beta$ glycosidic bonds. Extracted from green terrestrial and submarine plants and animals, such as wood, cotton, bacteria, and capsules, CNC is well known to possess a high degree of polymerization, high purity, high Young's modulus, high crystallinity, high strength, and ultra-fine structure [3] [4]. It also exhibits great potential for the applications in reinforcing materials [5], capacitors, and composite films [6] [7], as well as in antimicrobial [8], adsorbent [9] and medical materials [10] [11] [12] [13].

Preparing CNC in a green and efficient way is still problematic in the scientific research. CNC is typically prepared by acid hydrolysis or

2,2,6,6-tetramethylpiperidine-1-oxide (TEMPO) mediated oxidation. During the process of acid hydrolysis, $64 \mathrm{wt} \%$ sulfuric acid is used to hydrolyze lignocellulose at $45^{\circ} \mathrm{C}$ for $45 \mathrm{~min}$, after which $\mathrm{CNC}$ is obtained by precipitation dialysis; Hamad and his coworkers prepared CNC with $89.1 \%$ crystallinity using this method [14]. Acid hydrolysis requires excessive amounts of acid, which leads to environmental problems, and the dialytic removal of acid usually takes 4 - 5 days, to give CNC in low yields (20\% - 30\%). On the other hand, TEMPO-mediated oxidation produces CNC using TEMPO as the oxidation catalyst and sodium hypochlorite/bromide to oxidize the fragmented amorphous zones of cellulose. Saito et al. prepared CNC in this manner in yields of $65 \%-95 \%$ [15]. In addition, the TEMPO catalyst is expensive, toxic, and corrosive, which is not convenient for industrial applications.

Herein, we presented a novel method for extracting CNC from eucalyptus, namely the tetrahydrofuran/water mixed solubilization (TWMS) method; this mixed-solvent method is environmentally friendly and inexpensive, and is high-yielding when compared to acid-hydrolysis methods. The CNC produced by TWMS was characterized by X-ray powder diffractometry (XRPD), zeta potential (ZP) measurements, particle size distribution (PSD) (by DLS), Fourier-transform infrared (FT-IR) spectroscopy, ultraviolet-visible (UV-Vis) spectroscopy, and transmission electron microscopy (TEM). In addition, as toxicity analyses for CNC have rarely been reported, we subjected the CNC prepared in this manner to cytotoxicity testing and zebrafish-embryo toxicity testing. Zebrafish is a common model organism in the life sciences field. They are small, inexpensive to breed, have a short reproductive cycle, a large spawning volume, can be fertilized in vitro, and develop rapidly. Zebrafish have been widely used as a modern experimental animal model [16] [17]. Some drugs, when administered at doses higher than $0.3 \mathrm{mg} / \mathrm{mL}$ are teratogenic toward zebrafish embryos and lethal to juveniles. 


\section{Experimental}

\subsection{Materials}

Eucalyptus was sourced from Gaofeng Forest Farm in Guangxi Province, China. The eucalyptus hardwood was dried and crushed, and then sieved through a 150- $\mu \mathrm{m}$ pore-size mesh. Analytically pure nitric acid, anhydrous ethanol, sodium hydroxide, tetrahydrofuran, sodium hypochlorite, sulfuric acid, and hydrochloric acid were all produced by the Beijing Chemical Plant. Artificial seawater was reverse osmosis water produced by the Tianjin Zhongyan Marine Bioscience Co., Ltd. and had a salt concentration of $28 \%(w / w)$.

\subsection{CNC Preparation Methods}

\subsubsection{The Tetrahydrofuran/Water Mixed Solubilization (TWMS) Method} Eucalyptus (35 g) was loaded into a high-pressure stainless-steel reactor equipped with a stirring impeller. Tetrahydrofuran/water $(350 \mathrm{~mL} ; 6: 4 \mathrm{v} / \mathrm{v})$ was then introduced to the reactor. The fractionation reaction was conducted at $170^{\circ} \mathrm{C}$ for 1 $\mathrm{h}$ with stirring at $400 \mathrm{rpm}$ under a pressure of $100 \mathrm{MPa}$. At the end of the reaction, the mixture was filtered by vacuum filtration and the residual solid (RS) was thoroughly washed with 3:2 (v/v) tetrahydrofuran/water followed by distilled water $(3 \times)$. The filtrate was placed in a glass flask and bleached with a solution of sodium hypochlorite and sodium hydroxide mixture in a 25:2 (mL:g) ratio with a solid-to-liquid ratio of 1:20 (g:mL), followed by reacting in a shaker at $50^{\circ} \mathrm{C}$ for $2 \mathrm{~h}$. The bleaching step was repeated three times. The slurry was then centrifuged until the $\mathrm{pH}$ of the supernatant was neutral. Finally, the resulted solution was diluted to $0.5 \mathrm{wt} \%$ with water, followed by ultrasonication for $1 \mathrm{~h}$ to obtain the CNC suspension.

\subsubsection{The nitric Acid-Sodium Hydroxide Hydrolysis (NSH) Method}

Eucalyptus ( $35 \mathrm{~g}$ ) was placed in a flask in $\mathrm{pH} 12.0$ sodium hydroxide solution in a solid-to-liquid ratio of 1:20 (g:mL). The flask was then set in a $60^{\circ} \mathrm{C}$ water bath for $75 \mathrm{~min}$, after which the RS was washed with distilled water, collected by filtration, and dried $60^{\circ} \mathrm{C}$ in an oven. The dried powder was placed in a flask with $\mathrm{pH} 3.0$ nitric acid solution at a solid-to-liquid ratio of 1:20 (g:mL) $75 \mathrm{~min}$ in a $60^{\circ} \mathrm{C}$ water bath. Eucalyptus cellulose was obtained by neutralizing the residual acid, washing and filtering with distilled water, and drying in an oven. The extracted cellulose was placed in a $100-\mathrm{mL}$ three-port flask, fixed on an iron platform with an agitator, placed in a constant temperature water bath, and a prepared 30:1 (w/w) sulfuric acid solution was slowly dripped into the flash with stirring. The reaction temperature was set to $80^{\circ} \mathrm{C}$. After $8 \mathrm{~h}$, the mixture was cooled, and deionized water was added to the mixture with a deionizedwater:reactant ratio of $5: 1(\mathrm{v} / \mathrm{v})$ to terminate the reaction. After 90 min of ultrasonication, the lower sediment was allowed to stand for $8 \mathrm{~h}$, after which it was centrifuged and the supernatant in the centrifuge tube discharged once per centrifugation. The lower sediment was mixed with water and then centrifugally washed at $300 \mathrm{rpm}$ so that the repeatedly washed suspension in the centrifuge 
tube did not resettle. CNC was obtained by transferring the suspension to a dialysis bag and placing it in deionized water at room temperature. The relative molecular weight of the dialysis bag was 8000 - 14,000 Da.

\subsubsection{Nitric Acid-Ethanol Hydrolysis (NEH) Method}

Irradiated eucalyptus powder $(35 \mathrm{~g})$ of was placed in a flask in a $3: 1(\mathrm{v} / \mathrm{v}) \mathrm{ni}-$ tric-acid/ethanol solution. A reflux condenser was attached to the flask, after which it was heated in a boiling water bath until the powder whitened. Eucalyptus cellulose was obtained by washing the residue with the nitric-acid/ethanol mixture, then with hot water to neutrality, washing twice with absolute ethanol, after which it was collected by vacuum filtration and dring. The extracted cellulose was then treated as described in section 1.2.2.

\subsection{Morphology and Spectroscopy of the as-Prepared CNC}

\subsubsection{Zeta Potential Measurements}

All experiments were carried out using a dilute (0.5 wt\%) CNC suspension. A Zetasizer Nano-ZS90 instrument (Malvern Instruments) was used to evaluate the colloidal stabilities (zeta potential and size) of CNC (prepared by TWMS) suspensions based on electrophoretic light scatting at $25^{\circ} \mathrm{C}$.

\subsubsection{Determining Particle Size by Dynamic Light Scattering (DLS)}

The $0.5 \mathrm{wt} \% \mathrm{CNC}$ suspension was diluted with distilled water to a ratio of 1:10 $(\mathrm{v} / \mathrm{v})$. CNC DLS size-distribution experiments were performed in duplicate with the above-mentioned Zetasizer Nano-ZS90 instrument at $25^{\circ} \mathrm{C}$.

\subsubsection{FT-IR Spectroscopy}

The $0.5 \mathrm{wt} \% \mathrm{CNC}$ suspension was freeze-dried. A 1-mg sample of the freeze-dried CNC powder was collected and mixed with $200 \mathrm{mg}$ of dry $\mathrm{KBr}$ powder. FT-IR spectra were recorded using a VERTER 22FT-IR spectrometer (Bruker Optics, Germany) over the $400-2000 \mathrm{~cm}^{-1}$ range at a resolution of $8 \mathrm{~cm}^{-1}$.

\subsubsection{Transmission Electron Microscopy (TEM)}

The CNC samples were subjected to TEM on a Hitachi HT7700 microscope (Hitachi, Japan). The sample was diluted to $0.01 \mathrm{wt} \%$ with water and $20 \mu \mathrm{L}$ of the dispersion was drop-cast onto a freshly glow-discharged carbon-coated copper grid. The sample was negatively stained with $2 \mathrm{wt} \%$ phosphotungstic acid solution ( $\mathrm{pH}$ 6.2) for $5 \mathrm{~min}$. After removal of the excess solution, the sample was dried at room temperature prior to TEM imaging. The sizes of the CNC particles were determined using an image-analysis system operating at $120 \mathrm{kV}$.

\subsubsection{X-Ray Powder Diffractometry (XRPD)}

The freeze-dried powder of the $0.5 \mathrm{wt} \% \mathrm{CNC}$ suspension was subjected to XRPD. XRPD patterns were acquired using an X-ray powder diffractometer (Rigaku SmartLab, Japan) with Ni-filtered $\mathrm{Cu} \mathrm{K} \alpha$ radiation at $45 \mathrm{kV}$ and 200 $\mathrm{mA}$. Diffraction data were collected in the $5^{\circ}-60^{\circ} 2 \theta$ range at a rate of $4^{\circ} / \mathrm{min}$. 
The relative crystallinity index (CrI) of CNC was determined using the XRD peak-height method and calculated using Equation (1):

$$
\mathrm{Crl}=\frac{I_{002}-I_{a m}}{I_{002}} \times 100 \%
$$

where, $\mathrm{I}_{002}$ is the intensity of the peak corresponding to the (002) lattice diffraction at $2 \theta \approx 22.3^{\circ}$, which represents both crystalline and amorphous regions, and $\mathrm{I}_{\mathrm{am}}$ is the diffraction intensity of the amorphous fraction at $2 \theta \approx 18.3^{\circ}$ [18] [19].

\subsubsection{UV-Vis Spectroscopy}

Aqueous $0.5 \mathrm{wt} \% \mathrm{CNC}$ suspensions were subjected to UV-Vis spectroscopy over the $200-800 \mathrm{~nm}$ wavelength range using a UV-vis spectrophotometer (Shanghai Jinhe Instrument Co. Ltd., China).

\subsection{Evaluating Toxicity}

\subsubsection{Cytotoxicity Assay}

Kunming mice (six male and six female aged 5 - 6 weeks, provided by the Laboratory Animal Canter of the Academy of Military Medical Sciences) weighing 20 - $22 \mathrm{~g}$ were selected for this experiment. The $0.5 \mathrm{wt} \% \mathrm{CNC}$ suspension was administered at the maximum intragastric dose $(1 \mathrm{~mL} / \mathrm{rat})$ at one time. The mice were observed for 14 days after intragastric administration, with mortality recorded. Any deceased mice were dissected for tissue examination.

\subsubsection{Zebrafish-Toxicity Assay}

The organs and tissue in zebrafish began to form from the gastrointestinal stage, which was further divided into four stages, such as the 50\%-outsourcing stage, the $75 \%$-outsourcing stage, the $90 \%$-outsourcing stage, and the tail bud stage. Zebrafish (Danio rerio, wild-type TU strain) were used to study the early larvae of zebrafish that developed to the 50\%-outsourcing stage; i.e., 6-h embryos after sperm, and 3-d larvae after fertilization. Zebrafish were cultured in the artificial seawater at $28.5^{\circ} \mathrm{C}+1^{\circ} \mathrm{C}$. An artificial light source was used to regulate the zebrafish life cycle, and an alternating $14 \mathrm{~h}$ light $/ 10 \mathrm{~h}$ dark illumination sequence was used. The zebrafish were fed with 48 -h-incubated (in reverse osmosis water) shrimp once a day at noon.

Embryo collection: the egg collection dish was placed at the bottom of the aquarium immediately after the light was turned on and the zebrafish began to approach the light. After spawning, the fertilized eggs leak from the screen mesh to the bottom of the dish. The dish was removed immediately and fish eggs that sank to the bottom of the dish were removed by suction. Zebrafish eggs were collected every 20 - $30 \mathrm{~min}$, rinsed with water several times and then transferred to small dishes filled with artificial seawater for further culturing.

The $0.5 \mathrm{wt} \% \mathrm{CNC}$ suspension was diluted into $0.1,1.0$, and $2.5 \mathrm{mg} / \mathrm{mL}$ using artificial sea water. Zebrafish embryos and juveniles developed from $6 \mathrm{~h}$ after fertilization (6hpf) and from $3 \mathrm{~d}$ after fertilization (3dpf) were selected. Each group of 30 zebrafish was placed in $2 \mathrm{~mL} \mathrm{CNC}$ solutions at different concentra- 
tions, and 30 wild-type embryos were used as the control group. Experiments were repeated in triplicate at each concentration. The phenotype and survival rate of the $6 \mathrm{hpf}$ and $3 \mathrm{dpf}$ zebrafish were monitored under a microscope (OLYMPUS SZ61, Japan) for three consecutive days following the addition of the test solution to the original solution.

\section{Results and Discussion}

\subsection{CNC Yield}

The TWMS, NSH, and NEH extraction methods were compared in terms of the yield of CNC. Table 1 reveals that the TWMS method provided the highest yield of CNC (40.97\%), followed by NEH (33.05\%) and NSH (29.14\%). We presumed that the molecular weight of the hydrolysate varied greatly due to incomplete hydrolysis of the product extracted by acid. Since the solvent dissolved cellulose poorly, hence, the yield from acid hydrolysis was relatively low. However, the TWMS method could dissolve almost all short-chain celluloses to provide a relatively high extraction rate. In addition, we optimized the ratio of tetrahydrofuran to water in the mixed solvent by investigating the effects of 5:5, 6:4, and 7:3 volume ratios on the extraction rate of CNC. The results reveal that the extraction rate was the highest at a volume ratio of 6:4.

The mechanism for the extraction of CNC by using the TWMS method involved the swelling of cellulose fibers by the polar organic solvent, which weakened their internal hydrogen bonds. The molecular chains of cellulose between the hydrophilic crystalline surfaces could slip and peel under mechanical shear force to form one-dimensional nanowires; i.e., CNC (Figure 1). We found that the surface of the CNC was negatively charged, which we speculated was due to the oxidation of cellulose and the formation of negatively charged carboxylate groups on its surface during the mixed-solvent dissolution process. In this study, we also found that the amorphous region of cellulose was hydrolyzed to produce monosaccharides, such as glucose, that can be used to produce fuel and chemicals through fermentation.

\subsection{Spectroscopy}

The prepared CNC was characterized through ZP experiments, FT-IR and

Table 1. Yields of CNC using the three preparation methods.

\begin{tabular}{cccc}
\hline Preparation Method & Eucalyptus (g) & CNC (g) & Yield (\%) \\
\hline NSH & 35.00 & 10.12 & 29.14 \\
NEH & 35.00 & 11.57 & 33.05 \\
TWMS & 35.00 & 14.34 & 40.97 \\
\hline
\end{tabular}




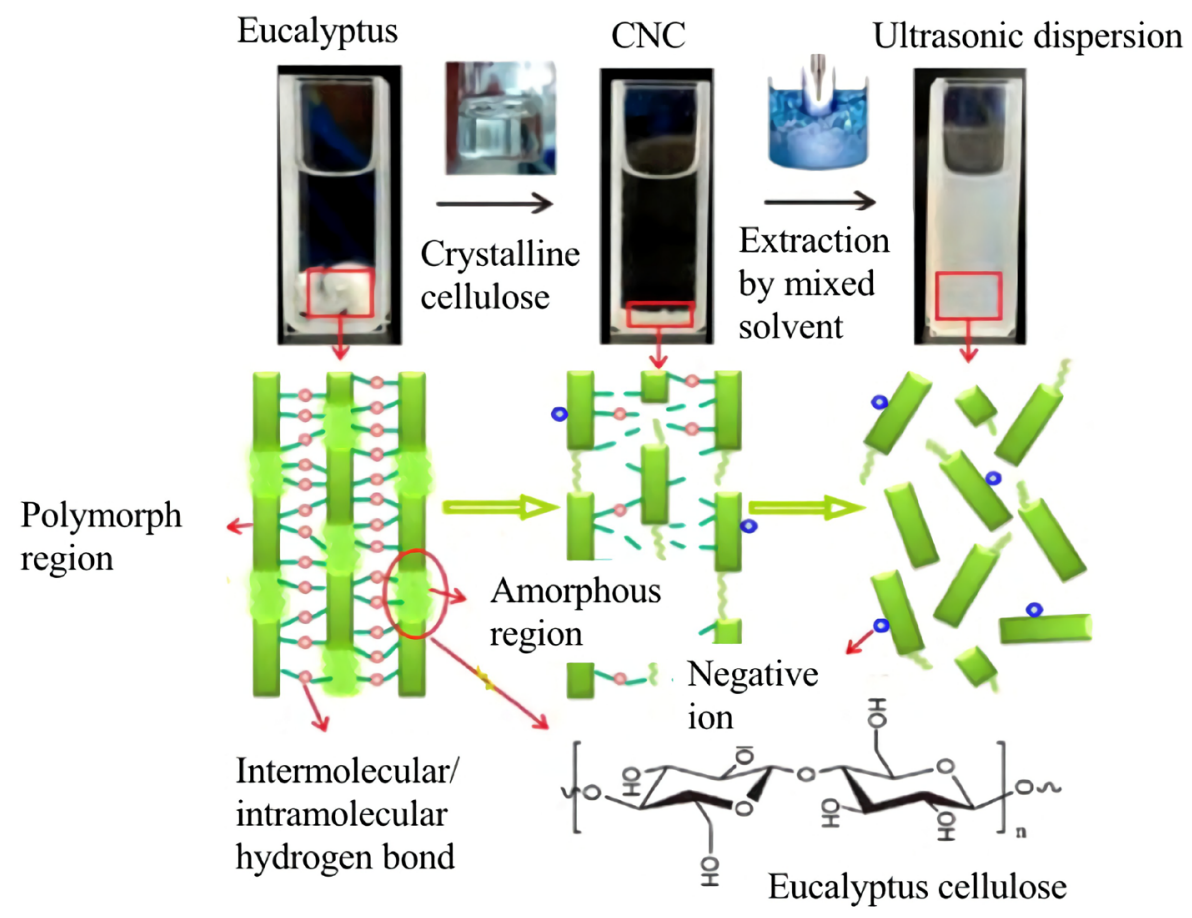

Figure 1. Mechanism for CNC extraction by the TWMS method.

UV-Vis spectroscopies, and PXRD. The morphology of CNC was examined by TEM, and the CNC particle-size distribution was determined by DLS experiments.

The ZP of the CNC prepared by the TWMS method was found to be $-56 \mathrm{eV}$ (Figure 2(A)). A larger surface potential results in a more stable CNC suspension; [20] hence, a $\mathrm{ZP}$ of $-56 \mathrm{eV}$ supports the CNC extraction mechanism shown in Figure 1, since mixed-solvent leaching made the cellulose surface negatively charged. The infrared spectrum displayed in Figure 2(B) exhibits an absorption peak at $897 \mathrm{~cm}^{-1}$ that corresponds to the $\beta$-d-glucose moiety, while the absorption peak at $1059 \mathrm{~cm}^{-1}$ is ascribable to the $\mathrm{C}-\mathrm{O}$ stretching vibrations of cellulosic alcohols. The absorption peaks at $1112 \mathrm{~cm}^{-1}$ and 1163 $\mathrm{cm}^{-1}$ correspond to the $\mathrm{C}-\mathrm{O}$ stretching vibrations of ether bonds and the $\mathrm{C}-\mathrm{C}$ skeleton, respectively, while the absorption peaks at $\sim 1371 \mathrm{~cm}^{-1}$ correspond to $\mathrm{C}-\mathrm{H}$ deformations. The peaks at $1664 \mathrm{~cm}^{-1}$ correspond to $-\mathrm{OH}$ bending vibrations of the cellulose lattice, while those at $2901 \mathrm{~cm}^{-1}$ and $3344 \mathrm{~cm}^{-1}$ correspond to $\mathrm{C}-\mathrm{H}$ (methylene) and $-\mathrm{OH}$ stretching vibrations, respectively [21] [22]. These absorption peaks suggest that the prepared eucalyptus CNC is a cellulose I polymorph.

UV-Vis spectroscopy (Figure 2(C)) shows that the CNC suspension is transparent, without any precipitates, suggesting that ultrasonic dispersion efficiently fibrillated the swollen cellulose. The XRPD pattern (Figure 2(D)) reveals characteristic diffraction peaks of cellulose at $2 \theta$ values of $16.6^{\circ}, 22.8^{\circ}$, and $34.5^{\circ}$, which indicates that the cellulose is entirely polymorph I [18] [19], that polymorphous and amorphous regions coexist during the extraction process, and 

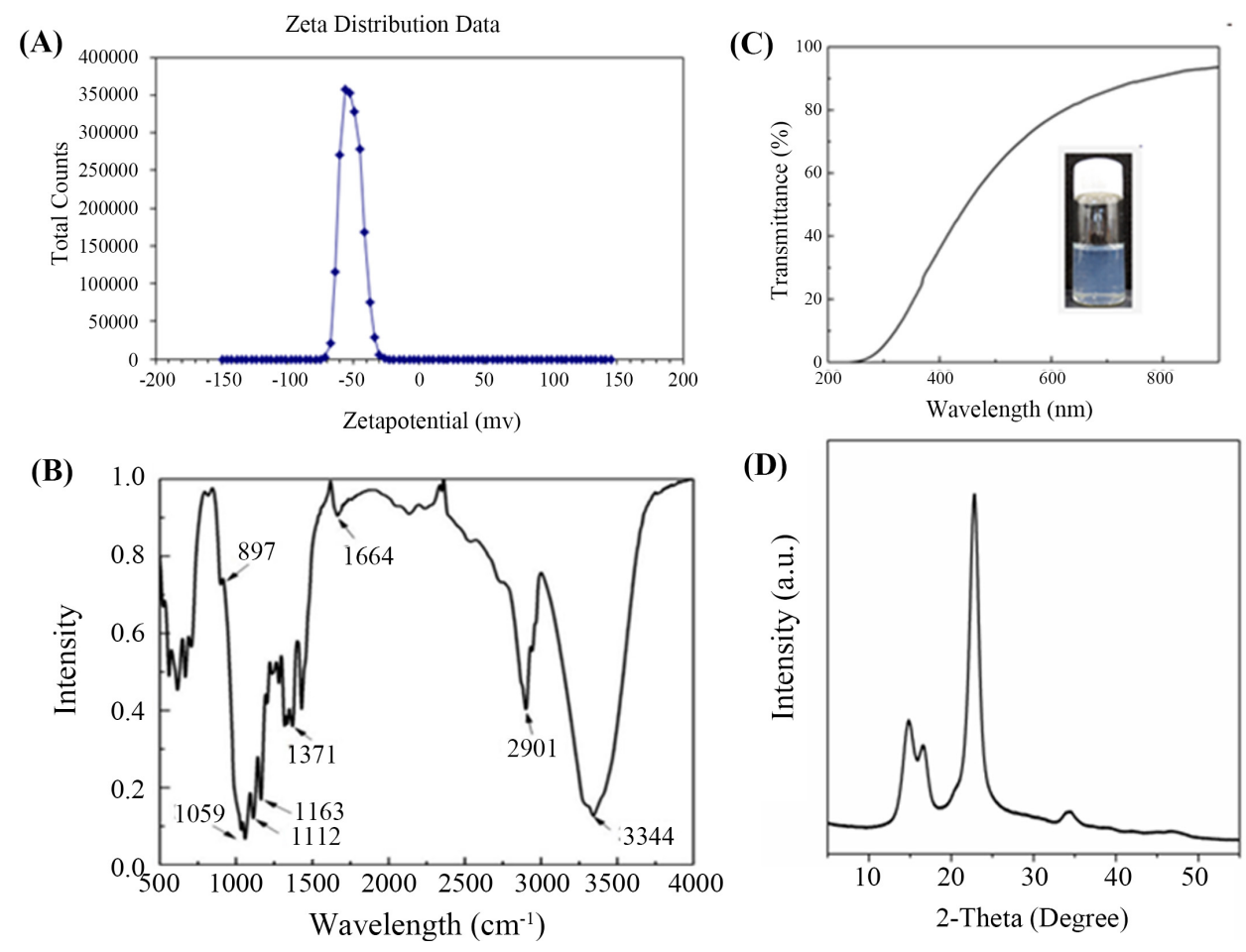

Figure 2. Characterizing the CNC prepared by the TWMS method. (A) Zeta-potential trace, (B) IR spectrum, (C) UV-Vis spectrum and a sample image, and (D) the XRPD pattern.

that the crystal structure of cellulose was not destroyed. The CrI of CNC was determined to be $73.3 \%$.

\subsection{CNC Morphology and Particle Size}

Figure 3 compares the morphologies and particle-size distributions of CNC extracted by both NEH and TWMS methods, which shows that the CNC fibers prepared by the two methods are uniformly dispersed and rod-shaped, respectively. The particles of the TWMS-extracted CNC exhibited a narrow size-distribution and low polydispersity, while the particle-size distribution of the CNC prepared by the NEH method was wider (with multiple peaks); hence its polydispersity is higher. A lower polydispersity is associated with more uniform particles [23]. The NEH method probably destroyed some polymorphous regions through strong-acid hydrolysis, resulting in a higher polydispersity. These results suggest that TWMS is a milder extraction method as compared to NEH method.

\subsection{Cytotoxicity Testing}

Fourteen days after intragastric administration [24], no abnormalities in body weight, or changes in behavior or histopathology were observed for the Kunming mice (Figure 4). It appears that the $0.5 \mathrm{wt} \% \mathrm{CNC}$ suspension is not cytotoxic.

\subsection{Zebrafish-Toxicity Testing}

CNC toxicity toward zebrafish larvae $6 \mathrm{~h}$ and $3 \mathrm{~d}$ after fertilization, and their 
toxic phenotypes, were examined at various test-solution concentrations. No teratogenic or lethal effects on embryonic development were observed at concentrations of $0.1,1.0$, or $2.5 \mathrm{mg} / \mathrm{mL}$, in terms of embryotoxicity (6hpf) and juvenile toxicity (3dpf) (Figure 5).

TEM images of CNC prepared by TWMS

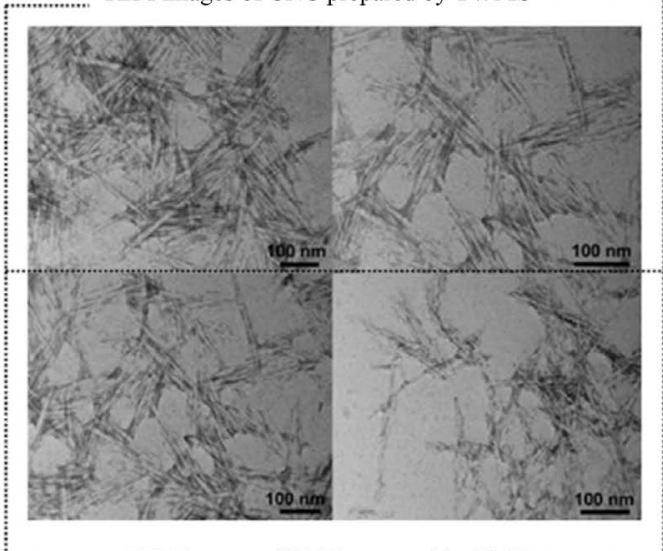

TEM images of CNC prepared by NEH
PSD of CNC prepared by TWMS
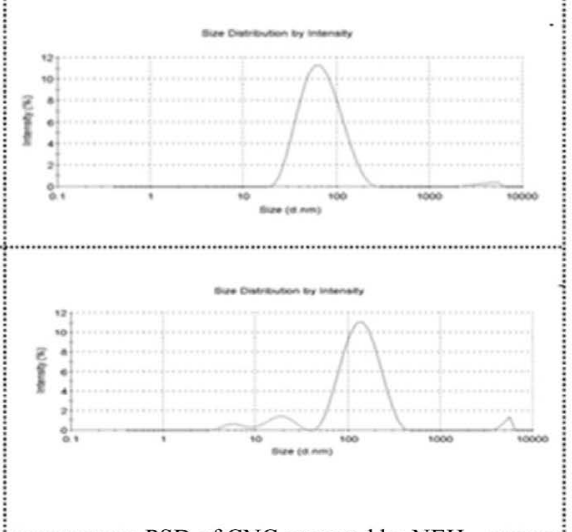

Figure 3. TEM images and particle-size distributions (PSDs) of CNC prepared by the TWMS (upper) and NEH (lower) methods.

6 male mice

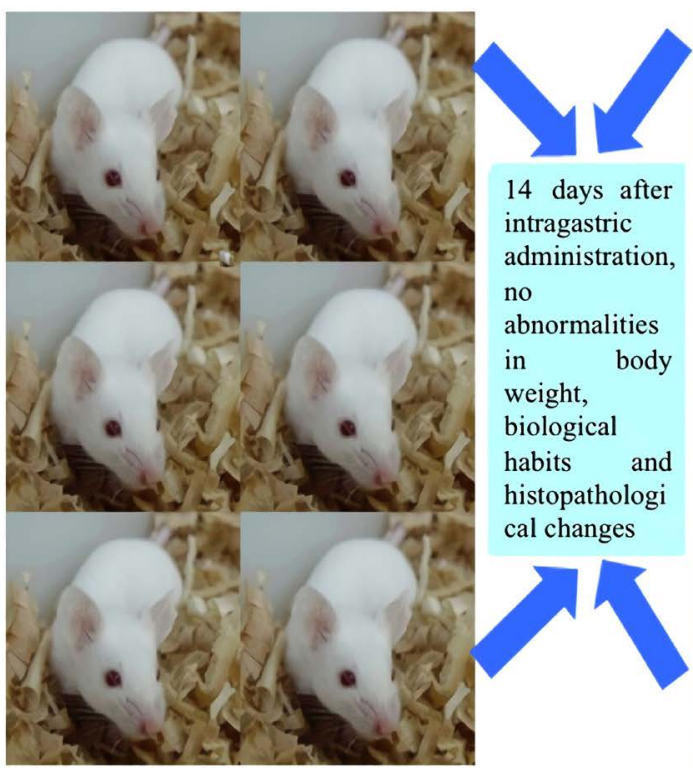

Figure 4. CNC cytotoxicity testing.
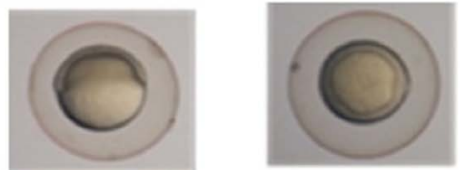

$50 \%$ outsourcing period $6 \mathrm{hpf}$ after fertilization
6 female mice
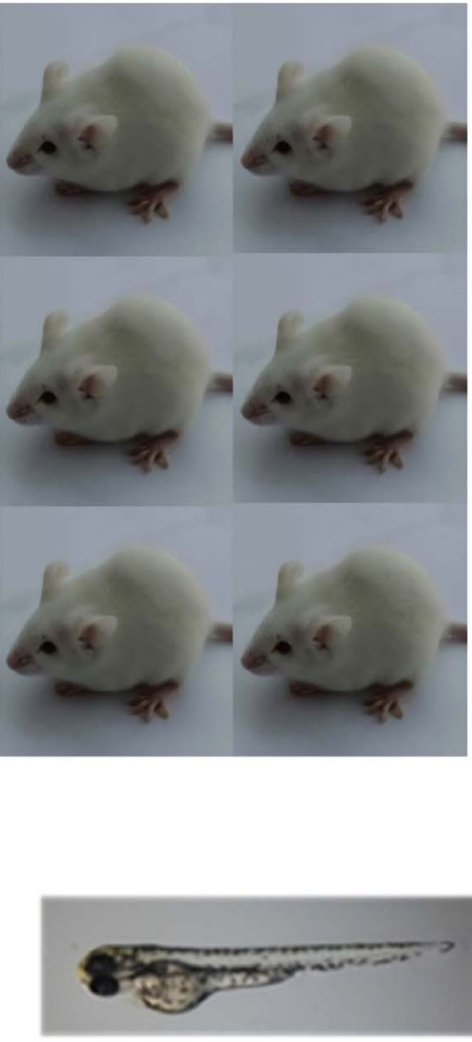

3dpf juvenile

Figure 5. Images of zebrafish embryos (6 hpf) and a juvenile (3 dpf). 


\section{Conclusions}

In this study, CNC was extracted from eucalyptus, with 6:4 (v/v) tetrahydrofuran/water solvent. CNC was obtained by breaking the hydrogen bonds between cellulose molecules. Compared with traditional acid hydrolysis methods, the TWMS method produced CNC in a higher yield (40.97\%). In addition, TWMS is a milder method for preparing CNC, since tetrahydrofuran has a low boiling point $\left(65^{\circ} \mathrm{C}\right)$ and can be recycled by distillation, which made the process is green and environmentally friendly.

CNC extracted by the TWMS and NEH methods was characterized by ZP measurements, FT-IR and UV-Vis spectroscopies, XRPD, TEM, and DLS experiments. The TWMS-extracted CNC particles have an average diameter of about $20 \mathrm{~nm}$ and are about $40 \mathrm{~nm}$ long; they are uniformly particle-size distributed, with a $\mathrm{ZP}$ of $-56 \mathrm{eV}$, and are cellulose type-I polymorphs with a CrI of $73.3 \%$. The CNC was extracted with its crystal structure intact.

Toxicity testing showed that $0.5 \% \mathrm{CNC}$ is a safe concentration since it was not toxic to mice. Zebrafish-toxicity testing showed that a $2.5 \mathrm{mg} / \mathrm{mL} \mathrm{CNC} \mathrm{suspen-}$ sion was not teratogenic or lethal to zebrafish embryos or juveniles, hence the extracted CNC could be potentially compatible with food and medical applications.

\section{Conflicts of Interest}

The authors declare no conflicts of interest regarding the publication of this paper.

\section{References}

[1] Ye, D.Y., Huang, H., Fu, H.-Q., et al. (2006) Advances in Cellulose Chemistry. Journal of Chemistry Industry and Engineering (China), 57, 1782-1791.

[2] Hubble, M.A., Rojas, O.J., Lucia, L.A., et al. (2008) Cellulosic Nanocomposites: A Review. BioResources, 3, 929.

[3] Sadeghifar, H., Filpponen, I. and Clake, S.P. (2011) Production of Cellulose Nanocrystals Using Hydrobromic Acid and Click Reactions on the Surface. Journal of Materials Science, 46, 7344-7348. https://doi.org/10.1007/s10853-011-5696-0

[4] Qin, Y., Cai, Z.Y., Wu, Y.Q., et al. (2012) Study Progress on Cellulose Nanofibril. Scientia Silvae Sinicae, 48, 145-151.

[5] Khan, A., Khan, R.A., Salmieri, S., et al. (2012) Mechanical and Barrier Properties of Nanocrystalline Cellulose Reinforced Chitosan Based Nanocomposite Films. Carbohydrate Polymers, 90, 1601-1608. https://doi.org/10.1016/j.carbpol.2012.07.037

[6] Zhao, Q. (2014) Research on the Preparation and Modification of Cellulose Nanocrystals and Its Application of Reinforced Composites. Donghua University, Shanghai.

[7] Xiong, Y., Wang, C., Wang, H., et al. (2018) Nano-Cellulose Hydrogel Coated Flexible Titanate-Bismuth Oxide Membrane for Trinity Synergistic Treatment of Super-Intricate Anion/Cation/Oily-Water. Chemical Engineering Journal, 337, 143-151. https://doi.org/10.1016/j.cej.2017.12.080 
[8] Liu, Y., Li, L., Pan, N., et al. (2016) Antibacterial Cellulose Acetate Films Incorporated with N-Halamine-Modified Nano-Crystalline Cellulose Particles. Polymers for Advanced Technologies, 28, 463-469. https://doi.org/10.1002/pat.3906

[9] Jin, L., Li, W., Xu, Q. and Sun, Q.C. (2015) Amino-Functionalized Nanocrystalline Cellulose as an Adsorbent for Anionic Dyes. Cellulose, 22, 2443-2456. https://doi.org/10.1007/s10570-015-0649-4

[10] Jackson, J.K., Letchford, K., Wasserman, B.Z., et al. (2011) The Use of Nanocrystalline Cellulose for the Binding and Controlled Release of Drugs. International Journal of Nanomedicine, 6, 321-330. https://doi.org/10.2147/IJN.S16749

[11] Mohanta, V., Madras, G. and Patil, S. (2014) Layer-by-Layer Assembled Thin Films and Microcapsules of Nanocrystalline Cellulose for Hydrophobic Drug Delivery. ACS Applied Materials \& Interfaces, 6, 20093-20101. https://doi.org/10.1021/am505681e

[12] Tang, L., Lin, F., Li, T., et al. (2018) Design and Synthesis of Functionalized Cellulose Nanocrystals-Based Drug Conjugates for Colon-Targeted Drug Delivery. Cellulose, 25, 4525-4536. https://doi.org/10.1007/s10570-018-1904-2

[13] Kontturi, E., Meriluoto, A., Penttila, P.A., et al. (2016) Degradation and Crystallization of Cellulose in Hydrogen Chloride Vapor for High-Yield Isolation of Cellulose Nanocrystals. Angewandte Chemie International Edition, 55, 14455-14458. https://doi.org/10.1002/anie.201606626

[14] Hamad, W.Y. and Hu, T.Q. (2010) Structure-Process-Yield Interrelations in Nanocrystalline Cellulose Extraction. The Canadian Journal of Chemical Engineering, 88, 392-402. https://doi.org/10.1002/cjce.20298

[15] Saito, T., Kimura, S., Nishiyama, Y. and Isogai, A. (2007) Cellulose Nanofibers Prepared by TEMPO-Mediated Oxidation of Native Cellulose. Biomacromolecules, 8 , 2485-2491. https://doi.org/10.1021/bm0703970

[16] Striillle, U., Scholz, S., Geisler, R., et al. (2012) Zebrafish Embryos as All Alternative to Animal Experiments-A Commentary on the Definition of the Onset of Protected Life Stages in Animal Welfare Regulations. Reprod Toxicol, 33, 128-132. https://doi.org/10.1016/j.reprotox.2011.06.121

[17] Peng, Y.R., Wei, Y.J., Ding, Y.F., et al. (2017) Development of Drug Toxicity and Novel Strategy for Toxicity of Chinese Materia Medica Based on Zebrafish Model. Chinese Traditional and Herbal Drugs, 48, 17-30.

[18] Chundawat, S.P.S., Bellesia, G., Uppugundla, N., et al. (2011) Restructuring the Crystalline Cellulose Hydrogen Bond Network Enhances Its Depolymerization Rate. Journal of the American Chemical Society, 133, 11163-11174. https://doi.org/10.1021/ja2011115

[19] Pinheiro, I.F., Ferreira, F.V., Souza, D.H.S., et al. (2017) Mechanical, Rheological and Degradation Properties of PBAT Nanocomposites Reinforced by Functionalized Cellulose Nanocrystals. European Polymer Journal, 97, 356-365. https://doi.org/10.1016/j.eurpolymj.2017.10.026

[20] Zhang, R.L. and Liu, Y. (2018) High Energy Oxidation and Organosolv Solubilization for High Yield Isolation of Cellulose Nanocrystals (CNC) from Eucalyptus Hardwood. Scientific Reports, 8, 16505-16516. https://doi.org/10.1038/s41598-018-34667-2

[21] Vieira, M.C., Antonio, C.R., Mendoza, M.A.M., et al. (2010) Cellulose Derivatives from Cellulosic Material Isolated from Agave lechuguilla and Fourcroydes. Cellulose, 9, 203-212. https://doi.org/10.1023/A:1020158128506

[22] Kaushik, A., Singh, M. and Verma, G. (2010) Green Composites Based on Ther- 
moplastic Starch and Steam Exploded Cellulose Nanofibrils from Wheat Straw. Carbonhydrate Polymers, 82, 337-345. https://doi.org/10.1016/j.carbpol.2010.04.063

[23] Zhang, H., Gao, H.K., Wang, Z., et al. (2018) Research and Characterization of Nanometer Cellulose Prepared by Hydrolysis of Microcrystalline Cellulose with Sulfuric Acid. Journal of Capital Normal University, 8, 31-35.

[24] Sahlin, H. and Nygren, H. (2001) Cytotoxicity Testing of Wound-Dressing Materials. Alternatives to Laboratory Animals, 29, 269-275.

https://doi.org/10.1177/026119290102900319 